\title{
Design and Implementation of Generic Information System for Local Trade Association based on Microsoft.NET
}

\author{
Changyu $\mathrm{Liu}^{1}$ and $\mathrm{Bin} \mathrm{Lu}^{2, *}$ \\ ${ }^{1}$ College of Mathematics and Informatics, South China Agricultural University, \\ Guangzhou 510642, China \\ ${ }^{2}$ School of Computer Science, Wuyi University, Jiangmen 529020, China \\ yezhich@gmail.com, "Ibscut@gmail.com (corresponding author)
}

\begin{abstract}
In this paper, we design and implement a generic information system with three-tier architecture for a specific local trade association based on Microsoft .NET. In the beginning, we analyze primary system requirements and divide the system into two fundamental components, i.e., the front desk component, and the background management component. The front desk component is equivalent to a local portal website, which mainly display information about the local trade association and provide login entry for its members. The background management component mainly provides releasing information of the local trade association and managing members of the association. Furthermore, for system design, we present details on architecture design, module design, and database design. Finally, we also illustrate the implementation of the system.
\end{abstract}

Keywords: generic information system, three-tier architecture, local trade association, Microsoft .NET

\section{Introduction}

With the development of science and technology, the rapid informatization has become a crucial determinant of international competitiveness of nations. Meanwhile, it brings also many potential benefits to an organization institution, such as excellent management mode, high circulate efficiency, and strong competition. Information level has already become an important metric to evaluate management effectiveness and service quality of organizations. As a result, all kinds of organizations, including various local trade associations, are trying to construct their own information systems. Information system is becoming one of the most important components for trade associations.

Different trade associations have their own needs for information systems, but there are some common requirements for these information systems. In the paper, we design and implement a generic management information system for local trade associations, which is suitable for the secondary development. Based on Microsoft .NET platform, the system is composed of four roles, four functional modules and five entities. In the following paragraphs, we illustrate our system from these aspects based on the principles and methods of software engineering.

\section{Requirement Analysis}

The requirement analysis is the first step of software lifecycle, and it is also a key process influencing project success. In software engineering, the requirement analysis involves many tasks, such as describing the functions and performance of a new product deeply, setting the constraints of software design and defining other effective demand [1-4]. Using requirement analysis technology, an experienced system analyst can derive the functions of systems from customer needs. 
For the required information system, its main functions are to release trade information about a specific local trade association and provide a friendly interactive platform for the members of the trade association. Thus, primary functions of the system are member management and other information management. Then, the required system is divided into four functional modules, which are login module, member management module, information releasing management module, and system management module, as follows.

(1) The information releasing management module. This module should provide the function that organizes a large amount of confused information, such as texts, pictures and videos, and releases the information reasonably and orderly.

(2) The member management module. Major functions of this module should are maintaining basic information of members belonging to the trade association, managing a talent pool, and maintaining information of organizations or association branches.

(3) The system management module. This module should provider system administrators with administrator management, system log management, system parameter setting, and sensitive words management. For the administrator management, the system should provide role management, permission assignment and permission adjustment. For the system log management, the functional requirement is to save records of operating on the whole system. For the system parameter setting, some necessary parameters setting of the whole system are required, such as number of records per page.

(4) The login module. This module should offer a friendly interface for different user to access. Some access control methods should be considered, such as controlling an account number not to login from different points at the same time.

\section{System Design}

\subsection{Architecture and Modules}

On the base of system requirement analysis, system design is easy to be developed from some aspects, including architecture design, database design, and so on. In this paper, we adopt popular three-tier $\mathrm{B} / \mathrm{S}$ architecture, which are the user presentation tier, the business processing logic tier, and the data access tier. Besides, some common components are put in an additional tier, i.e. common component tier.

Furthermore, from the perspective of business processing logic, the proposed information management system in this paper is divided into two major parts, which are front desk and background management. The two parts are then subdivided into several small parts in detail, corresponding to the requirement discussed in the previous section, as shown in Figure 1.

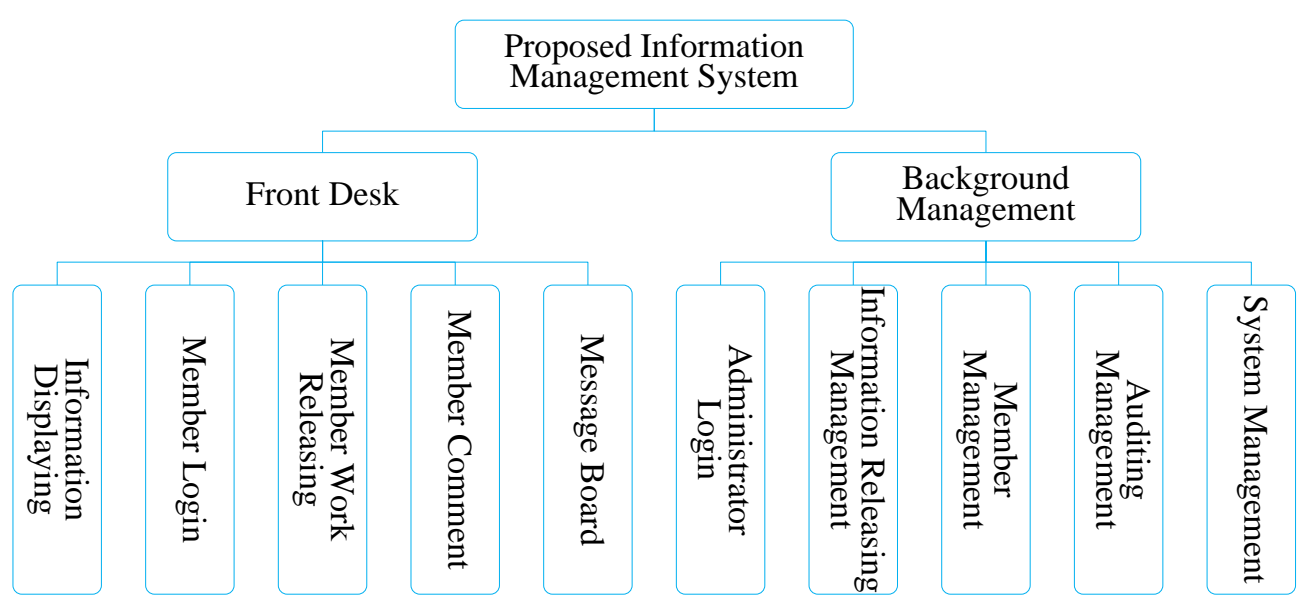

Figure 1. System Function Structure 


\subsection{Database Design}

Database design is an important ring of system design. The design of database structure can directly affect the efficiency of information system, and an excellent design of database structure can reduce the storage of database and achieve the integrality and consistency of database. According to the requirement analysis described above, we adopt the entity-relationship (ER) model to express the data relationships of the required system. The designed ER diagram is shown in Figure 2, by using Visio 2010 [5-6], an excellent tool for creating professional-looking charts to assist in understanding and analyzing. From Figure 2, it can be seen that there are eleven entities, which are the individual member information table INDIVIDUAL_MEMBER, the organization member information table ORGANZATION_MEMBER, the user table USERS, the administrator table ADMINISTRATORS, the comment table COMMENTS, the feedback table FEEDBACK, the feedback replying table FEEDBACK_REPLY, the information table INFORMATION, the information type table INFORMATION_TYPE, the individual work table INDIVIDUAL_WORKS, and the system log table SYSTEM_LOG.

\section{System Implementation}

We implement the proposed information system based on Microsoft .NET platform, including Visual Studio 2010, C\#, ASP.NET, Internet Information Services (IIS), Microsoft SQL Server and so on. Visual Studio 2010 is an integrated development environment [7], which does well in desktop applications, web applications, and office 


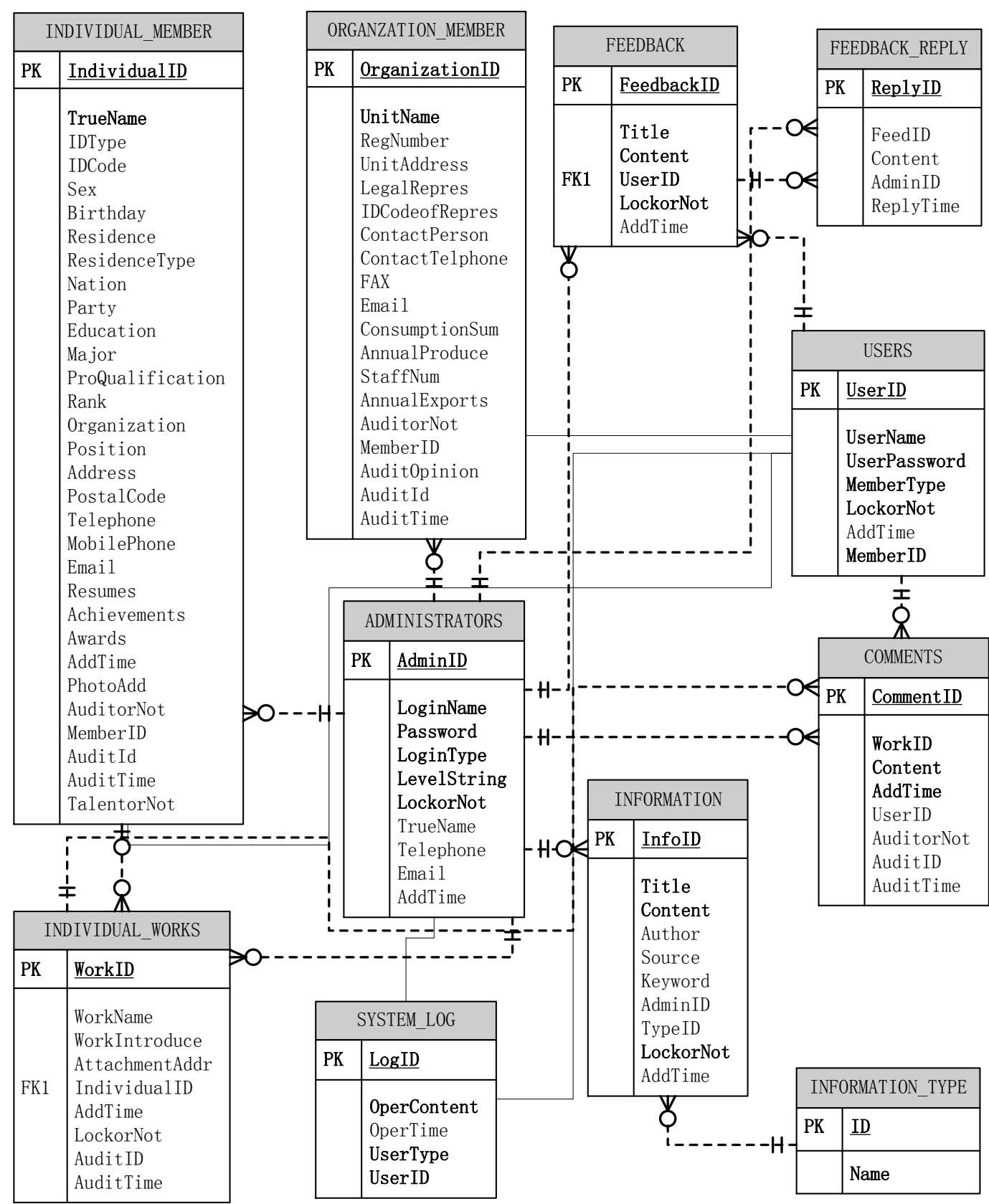

Figure 2. Entity-Relationship (ER) Model

Plugins and so on. We take the programming language of C\# [8] and ASP.NET [9] technology to perform the coding work of the proposed system. For the web server, we choose the IIS 6 [10], which is a web component of Windows produced by the Microsoft. Simultaneously, we adopt the Microsoft SQL Server 2008 [11] as the relational database management system (DBMS).

\subsection{Front Desk}

The front desk is equivalent to a local portal website, which mainly display information about the trade association and provide the login entry for members. In the front desk, individual members can release their own works and other members can comment these works. On the same time, members can leave words to the system administrator by message board. Besides, an authorized organization member can audit the information of individual members subject to its own. The front desk is relatively easy to be 
implemented by using the technology of ASP.NET, DIV and CSS, which often requires style of beautiful and atmospheric appearance. There are several page templates prepared for front desk commonly. So, the front desk is not to be described more here, and the emphasis is background management.

\subsection{Background Management}

\subsubsection{System Management Module}

On the basis of the requirement analysis, the system management module has four major functions, which are the administrator management, the system log management, the system parameter setting, and the sensitive words management. Then, we implement the four functions by several sub-modules.

For the administrator management, we mainly consider the permission assignment and permission adjustment of different administrator. We divide administrators into four different kinds of hierarchical roles, which are column administrator, organization administrator, system administrator and super administrator. Column manager can only manage these authorized columns, and the authorities on columns are viewing, addition, editing, and deletion and so on. In addition to the rights of column administrator, organization administrator has the permissions of organization member, such as managing individual members belonging to it. Similarly, system administrator has the permissions of column administrator, and it also has the permissions of system configuration, like system parameter setting, system log management and administrator management and so on. Super administrator has the permission of the above three administrator. On this basis, we can realize the functions of administrator addition, deletion and edition. There is an example of a system administrator addition shown in Figure 3.

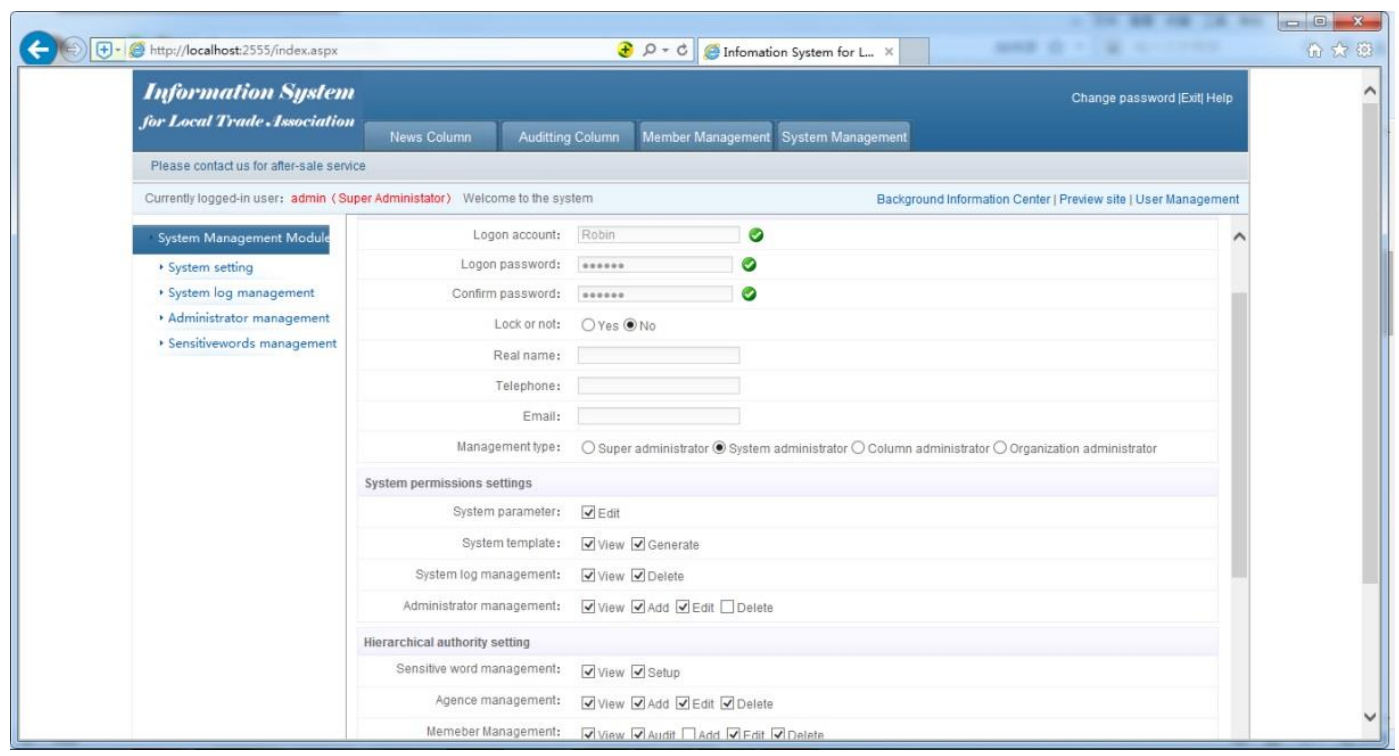

Figure 3. An Example of a System Administrator Addition

For the system log management, the log function can be invoked or not. Once the function is invoked, operation on the whole system can be logged and shown to the authorized administrator, shown in Figure 4. 


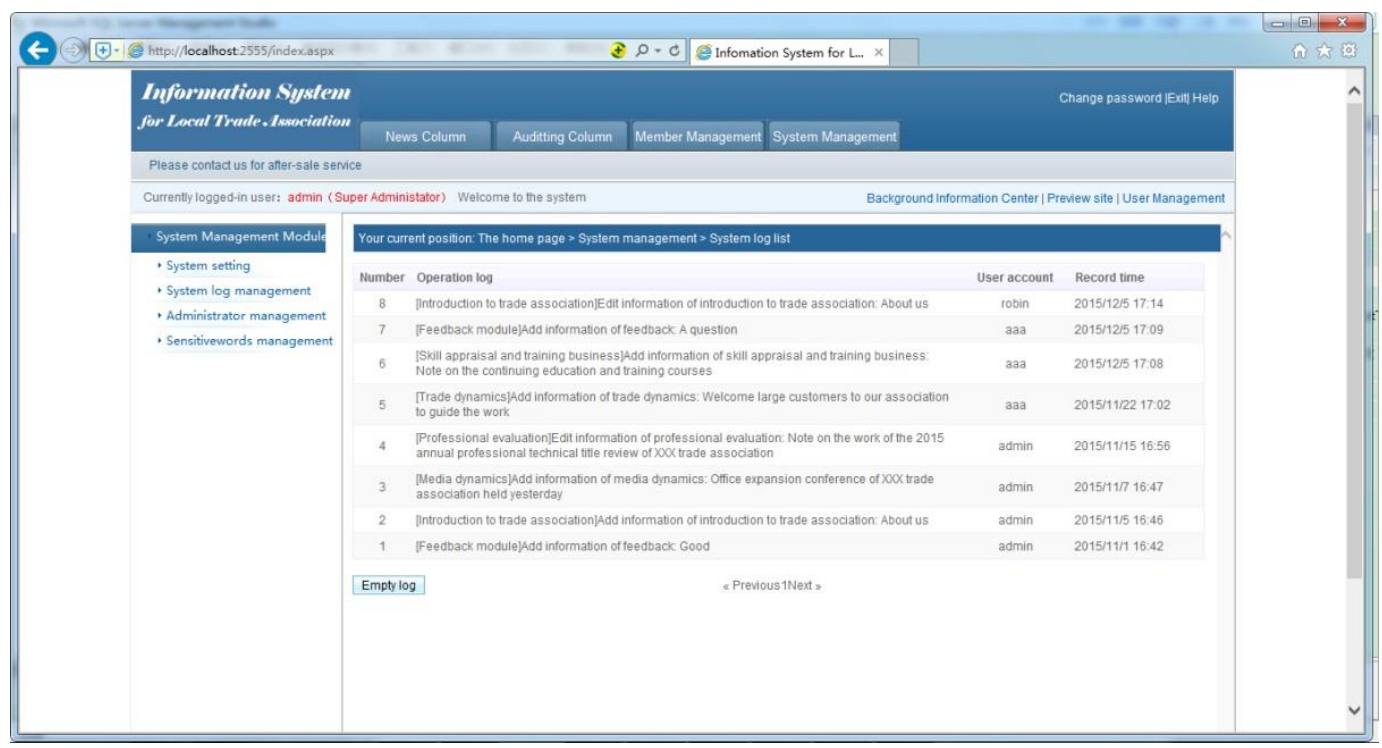

Figure 4. The Interface of the System Log Management

For the system parameter setting, system parameters are divided into four kinds, which are basic parameters, advanced parameters, paging parameters and attachment parameters. Basic parameters contain the website title, the domain name of website, recording number of website, key words of website, description of website, copyright information of website and so on. Advanced parameters consist of virtual directory, background management directory, file upload directory, file type for upload, file size for upload, SQL injection filtering, auditing or not for leave words, auditing or not for comments and so on. Paging

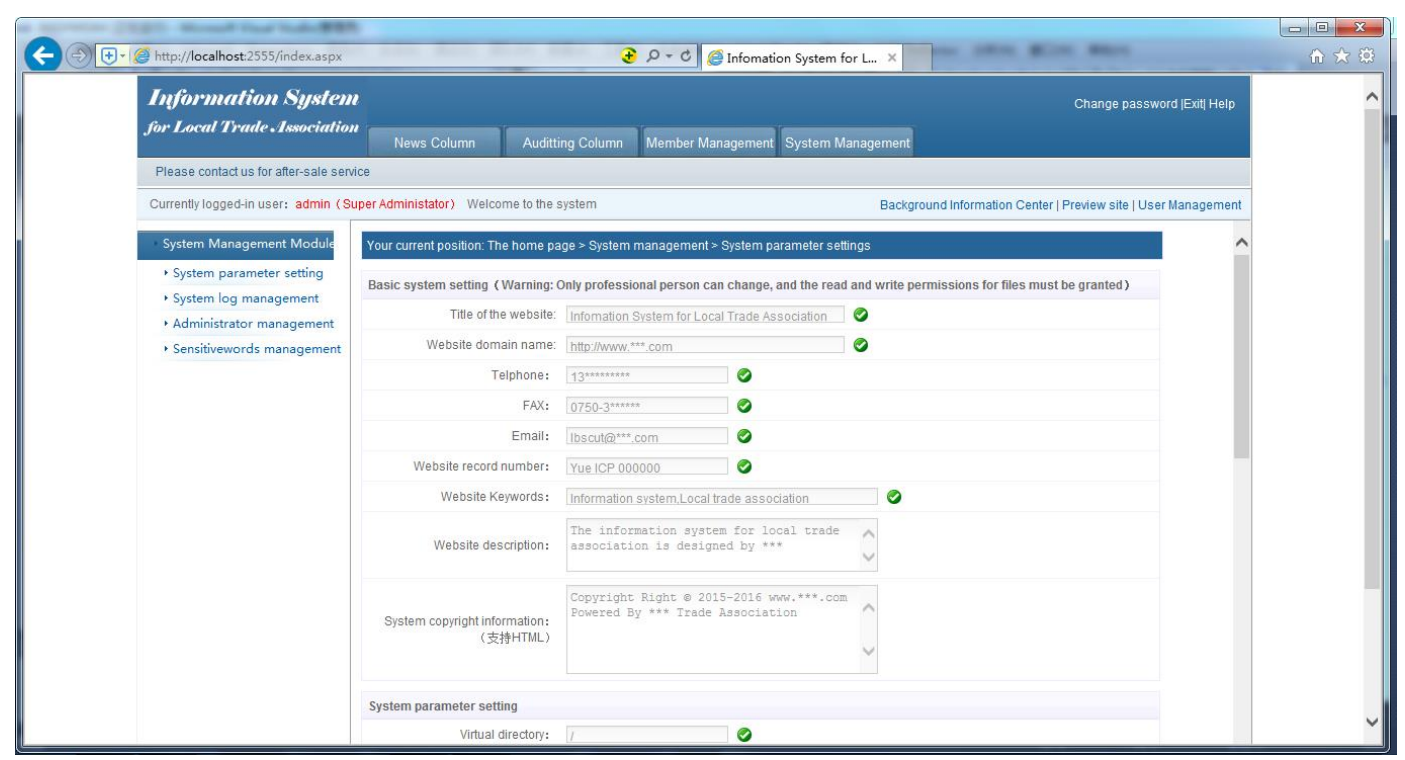

Figure 5. The Page of the System Parameter Setting

Parameters are related to record numbers of web pages about some columns. Attachment parameters are mainly related to pictures upload, which involves thumbnails, watermark and so on. The page of the system parameter setting is shown in Figure 5. After these system parameters are set successfully, they are saved in a file of XML to be called by other functions, shown in Figure 6 . 


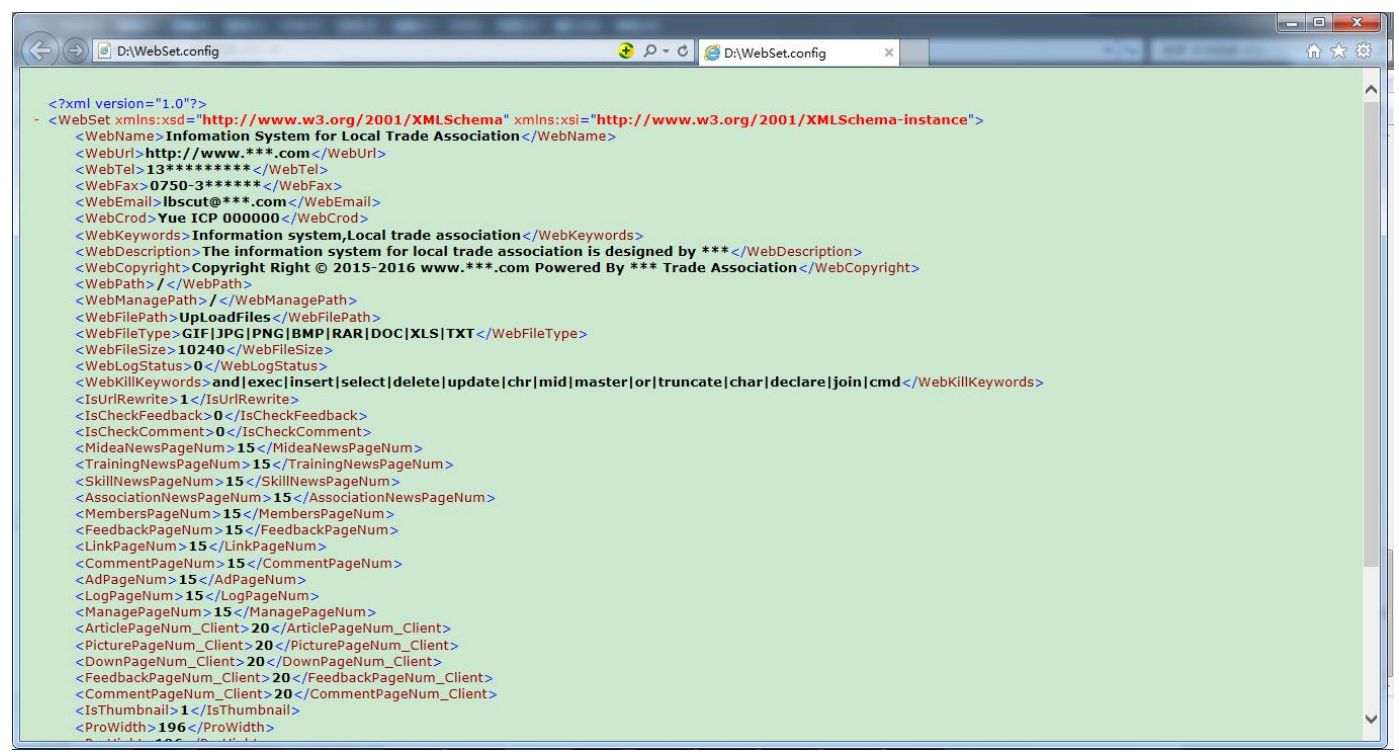

Figure 6. The XML File of System Setting

For the sensitive words management, this function is to filter those sensitive or dirty words when information is released to public. Figure 7 shows the sensitive word management web page. From Figure 7, we can see that every two sensitive words are

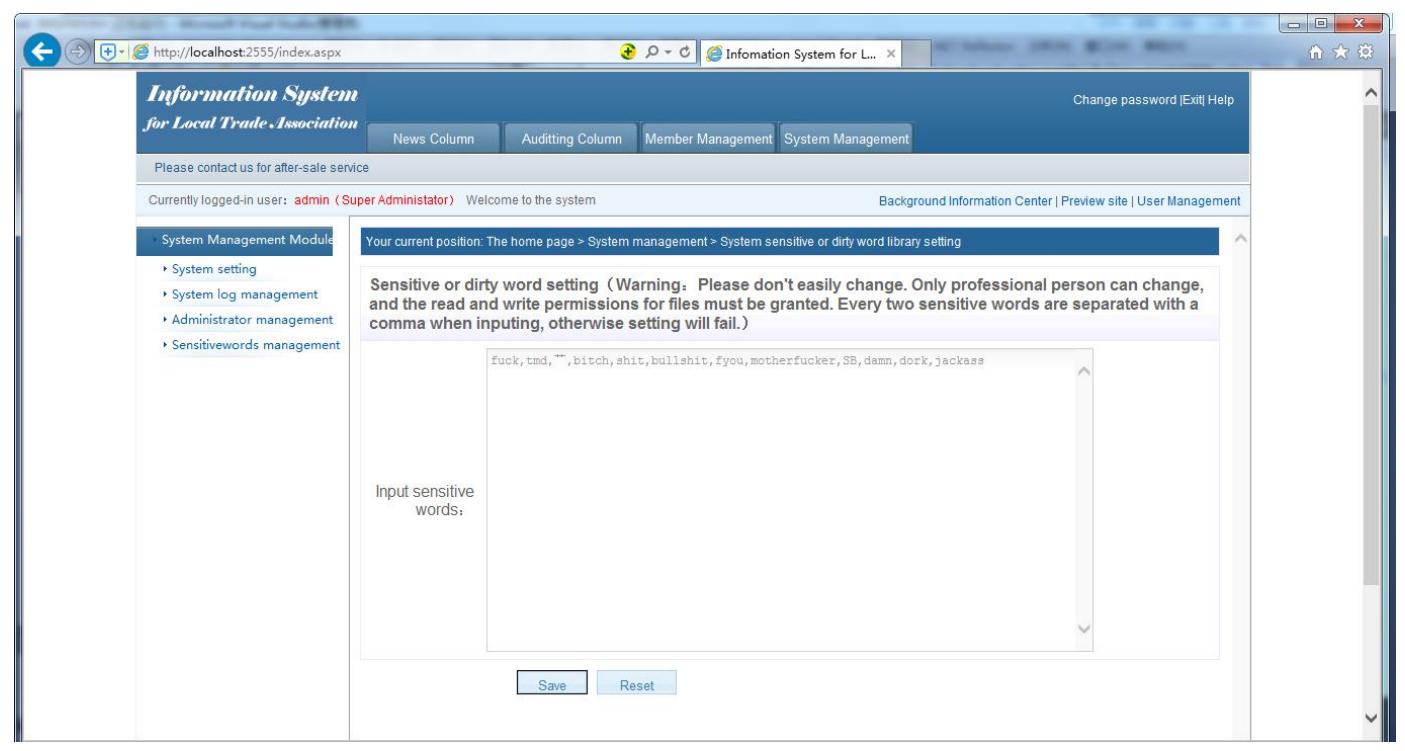

Figure 7. The Page of Sensitive Words Management

separated with a comma. By using commas, those sensitive words are written into a text file in a loop manner. The text file is saved in the root of the information system in web server in order to be conveniently called by other programs. We compare the released contents with the sensitive words of the text file to monitor the sensitive words through a classical algorithm when we release information. If the released contents contain sensitive words, a warning is given to us, shown in Figure 8. 


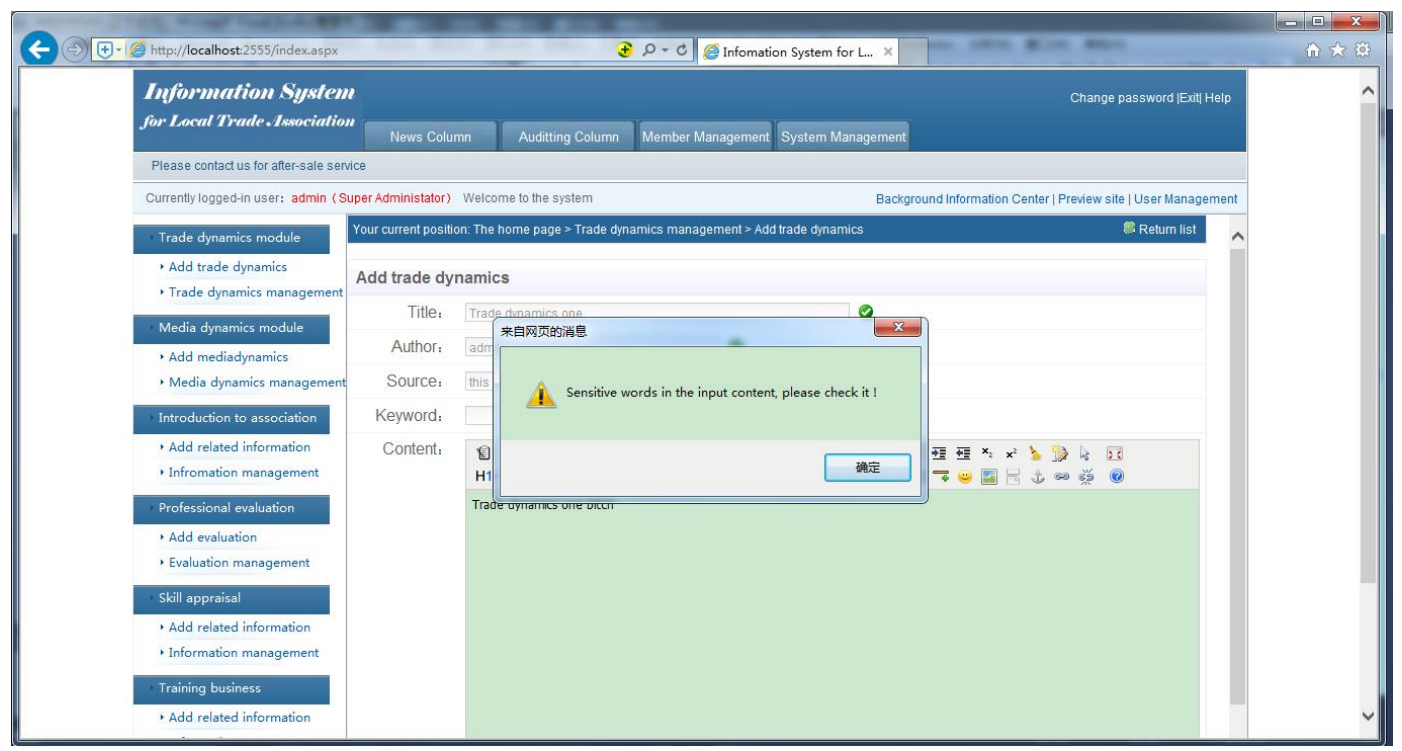

Figure 8. Monitoring Input Text and Giving A Warning

\subsubsection{Information Releasing Management Module}

There are six kinds of primary information, like introduction to trade association, trade dynamics, media dynamics, professional evaluation, skill appraisal and training business. There is a corresponding column to release related information for every kind. For example, information on trade association is released to the column of introduction of trade association. News about trade is released to the column of trade dynamic. News about trade from other media is reprinted to the column of media dynamics.

As mentioned above, there are six kinds of primary information, and it is possible that personnel or organization members and administrators are authorized to release information. If any information is released by personnel or organization members, authorized administrator must audit the information. Thus, that information is divided into two organizations for management, which are news management and auditing management. We choose a web-based online editor of open source to edit the information when we add or modify it.

\subsubsection{Member Management Module}

There are commonly two types of member in a trade association, including individual member and organization member. An individual member belongs to an organization member or not. Both individual member and organization member can submit or manage respective identity information and release some other information according to their own authority by the proposed system. Moreover, if an individual member belongs to an organization member, the organization member can audit the personal information and other information of the individual member, as mentioned above. If an individual member does not belong to any organization member, information released by his/her will be audited by a top level manager. Certainly, the authorized administrator can also submit the basic information of these members directly.

Besides, we establish a talent bank to enhance the management of individual member. Only an individual member in medium-grade or higher professional title can be identified as a talent. Once an individual member has talent identity, it has chances to take part in some activities as an evaluation expert. 


\subsubsection{Login Module}

The login module is mainly oriented to the demand of administrators, and its main function is to identify the role of administrator by the input information and assign accordingly their web pages. There are user name, password and verification code required to be input on the web page. Verification code technology is realized by cookie mechanism, and then the web browser accessing the system must support cookies. Moreover, web browser would be closed if there is more than three times for login error.

\section{Conclusion}

In this paper, we developed a three-tier generic information system for a local trade association base on Microsoft .NET platform, which generally aims at some local associations. With the exception of local trade associations, the proposed system can be used to local chamber of commerce, industry association, and alumni association of any university and so on. The system can help enhance information level of associations and effective communication among members. We achieved our predetermined target by the developed system. In the future, we want to optimize the system and further widen its applications.

\section{Acknowledgments}

This paper was supported by the Science and Technology Planning Project of Guangdong Province, China under Grant No. 2016A020210103, the Doctor Startup Foundation of Wuyi University under Grant No. 2014BS07, and the Basic Theory and Scientific Research Project of Jiangmen City under title "Empirical study and evolution mechanism on some social networks". We would like to thank anonymous reviewers for helpful comments.

\section{References}

[1] P. Herrmann and G. Herrmann, "Security requirement analysis of business processes", Electron. Commer. Res., vol. 6, no. 3-4, (2006), pp. 305-335.

[2] B. Lu, C. Liu and T. Zhao, "A three-tier salary management system for higher vocational colleges", Int. J. Multimed. Ubiq. Eng., vol. 10, no. 4, (2015), pp. 91-104.

[3] B. Lu, C. Liu and C. Li, "A J2EE based management information system for higher vocational colleges", Int. J. Smart Home, vol. 9, no. 1, (2015), pp. 69-80.

[4] B. Lu, C. Liu and W. Gao, "Research and design on auxiliary system for citation certificate of academic papers", Int. J. Smart Home, vol. 9, no. 10, (2015), pp. 69-76.

[5] Microsoft Visio, URL: https://fr.wikipedia.org/wiki/Microsoft_Visio.

[6] Professional Flow Chart \& Diagram Software | Microsoft Visio, URL: https://products.office.com/en-us/Visio/flowchart-software.

[7] Visual Studio - Microsoft Developer Tools, https://www.visualstudio.com/en-us/visual-studio-homepage-vs.aspx.

[8] C\# Tutorials, URL: https://msdn.microsoft.com/en-us/library/aa288436(v=vs.71).aspx.

[9] ASP.NET, URL: http://www.asp.net/.

[10] Internet Information Services (IIS), URL: https://msdn.microsoft.com/en-us/library/ee532514(v=vs.90).aspx.

[11] Microsoft SQL Server, URL: https://msdn.microsoft.com/en-us/library/mt590198(v=sql.1).aspx.

[12] H. Ken, "The opportunities for prepaid - the need for an international trade association", Card Tech. Tod., vol. 19, no. 6, (2007), pp. 10-11.

[13] A. Tsadimas, M. Nikolaidou, and D. Anagnostopoulos, "Handling non-functional requirements in information system architecture design”, In: ICSEA, (2009), pp. 59-64. 


\section{Authors}

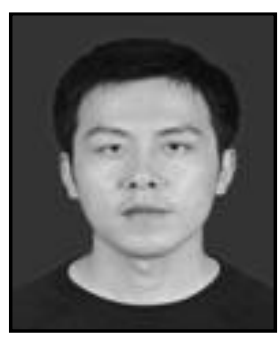

Changyu Liu, he received the $\mathrm{PhD}$ degree in 2015 from South China University of Technology, where he worked under the supervision of Prof. Shoubin Dong. He is currently a lecturer at the College of Mathematics and Informatics, South China Agricultural University. He was a visiting scholar at the School of Computer Science, Carnegie Mellon University, from September 2012 to October 2013, advised by Dr. Alex Hauptmann. Then, he worked with Prof. Mohamed Abdel-Mottaleb and Prof. Mei-Ling Shyu at the Department of Electrical and Computer Engineering, University of Miami, from October 2013 to September 2014. He serves as a reviewer for many international journals, such as Neural Computing and Applications, Security and Communication Networks, KSII Transactions on Internet and Information Systems, Journal of Computer Networks and Communications, and Tumor Biology. $\mathrm{He}$ is a Technical Program Committee member for many international conferences, such as AITA2016, IWWCN2016, MCSSE2016, and WCNE2016. His research interests include computer vision, pattern recognition, machine learning, bioinformatics, virtual reality, and multimedia analysis.

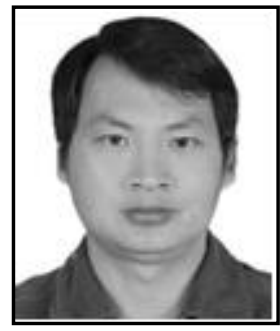

Bin Lu, he received the Ph.D. degree in Computer Application Technology, from South China University of Technology, Guangzhou, China, in 2013. In January 2014 he joined the School of Computer Science at Wuyi University. Currently, he is hired as an expert of performance evaluation of finance expenditure by the bureau of finance of Jiangmen city since October, 2014, and he is also a reviewer of the Journal of Yangtze River Scientific Research Institute since 2010. Now he is working at Wuyi University as a lecturer. He has been author/coauthor of more than twenty scientific papers in international journals and refereed conference proceedings over the past six years. His main research interests are focused on analysis of complex network and complex systems, computational intelligence and analysis of complex systems, data mining and big data. 